\title{
ACARDIAC TWIN- A UNIQUE COMPLICATION OF MONOZYGOTIC TWIN
}

\author{
Lavanya K. ${ }^{1}$, Dwarakanath L. ${ }^{2}$, Dhananjaya B. S. ${ }^{3}$, Padmini C. P.4, Indira N. ${ }^{5}$
}

${ }_{1}^{1}$ Final Year Postgraduate Student, Department of Obstetrics and Gynaecology, Sri Siddhartha Medical College and Research Centre, Tumkur, Karnataka, India.

2Professor and Unit Chief, Department of Obstetrics and Gynaecology, Sri Siddhartha Medical College and Research Centre, Tumkur, Karnataka, India.

${ }^{3}$ Professor, Unit chief and HOD, Department of Obstetrics and Gynaecology, Sri Siddhartha Medical College and Research Centre, Tumkur, Karnataka, India.

${ }^{4}$ Professor and Unit Chief, Department of Obstetrics and Gynaecology, Sri Siddhartha Medical College and Research Centre, Tumkur, Karnataka, India.

${ }^{5}$ Associate Professor, Department of Obstetrics and Gynaecology, Sri Siddhartha Medical College and Research Centre, Tumkur, Karnataka, India.

HOW TO CITE THIS ARTICLE: Lavanya K, Dwarakanath L, Dhananjaya BS, et al. Acardiac twin- a unique complication of monozygotic twin. J. Evolution Med. Dent. Sci. 2019;8(29):2371-2374, DOI: 10.14260/jemds/2019/519

\section{PRESENTATION OF CASE}

A 23-years-old gravida three abortion two reported to my hospital at 28 weeks of gestation. The patient is from a local village near to Tumkur district. The patient came with complaints of sudden abdominal distension since two days and breathlessness since two days. On examination, patient was diagnosed to have severe pre-eclampsia. Her clinical examination revealed a uterus of 32-34 weeks gestation.

Per vaginal examination showed well effaced cervix with patulous os. Her ultrasonography scan done on the same day reported twin intrauterine gestation with single placenta and a thin membrane separating the two foetuses- monochorionic diamniotic twins. Twin A of 26 weeks gestation with absent cardiac activity- suggestive of intra uterine foetal death with grossly increased liquor of $24 \mathrm{~cm}$. Twin B was acardiac acephalus.

Patient was counselled for termination of pregnancy and was induced with misoprostol and progressed to active labour and delivered a first twin A (Figure 1) dead female baby of weight 1000 gms and 12 minutes later followed by acardiac twin (Figure 2) of 700 gms. The second baby was acardiac acephalus. It had absent head, upper limbs and thoracic organs.

The placenta was 300 gms (Figure 3) with two umbilical cords. In Twin A, cord was long and oedematous, and had three vessels. The acardiac twin had short cord. Both twins shared the same placenta. Patient was transferred to ward after treatment for severe pre-eclampsia and was discharged on the $8^{\text {th }}$ postpartum day.

Multiple pregnancy accounts for $1.5 \%$ of all pregnancies with approximate perinatal morbidity and mortality of ten percent. The incidence varies widely. One percent of monozygotic twins accounts for monoamniotic twinning. Monozygotic twins have 2.5 times higher rate of congenital anomalies than in dizygotic or singletons.

'Financial or Other Competing Interest': None.

Submission 01-04-2019, Peer Review 05-07-2019,

Acceptance 11-07-2019, Published 22-07-2019.

Corresponding Author:

Dr. Dwarakanath L.,

Professor and Unit Chief,

Suraksha Hospital, SIT College Back Gate,

Tumkur, Karnataka, India.

E-mail:profdwarak@gmail.com

DOI: $10.14260 /$ jemds $/ 2019 / 519$
The incidence of acardiac twins is one in 35,000 pregnancies and 1 in hundred monozygotic twins. Acardiac twin is more among monozygotic twins of same gender and commonly seen among female twins.(1)
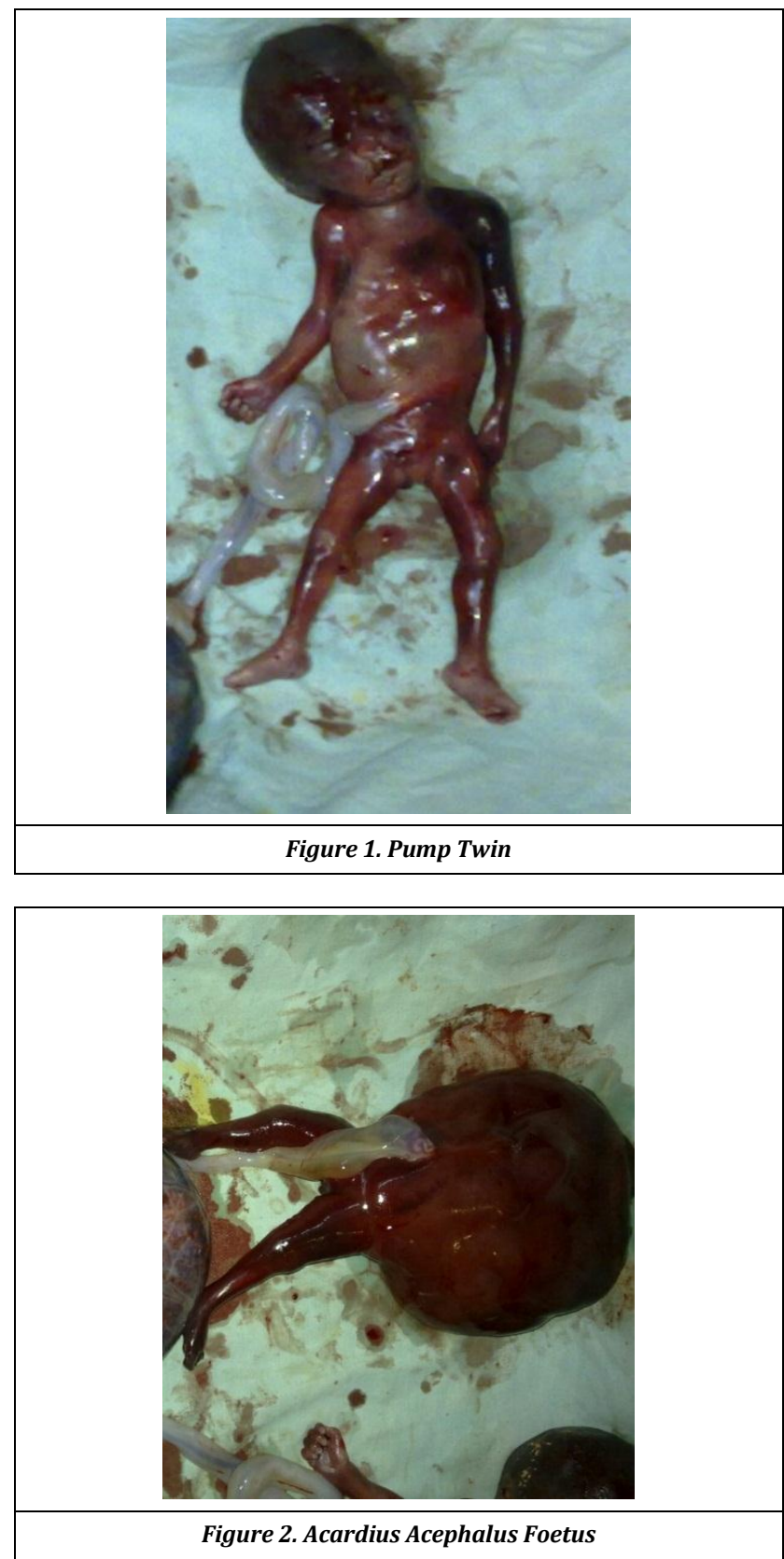

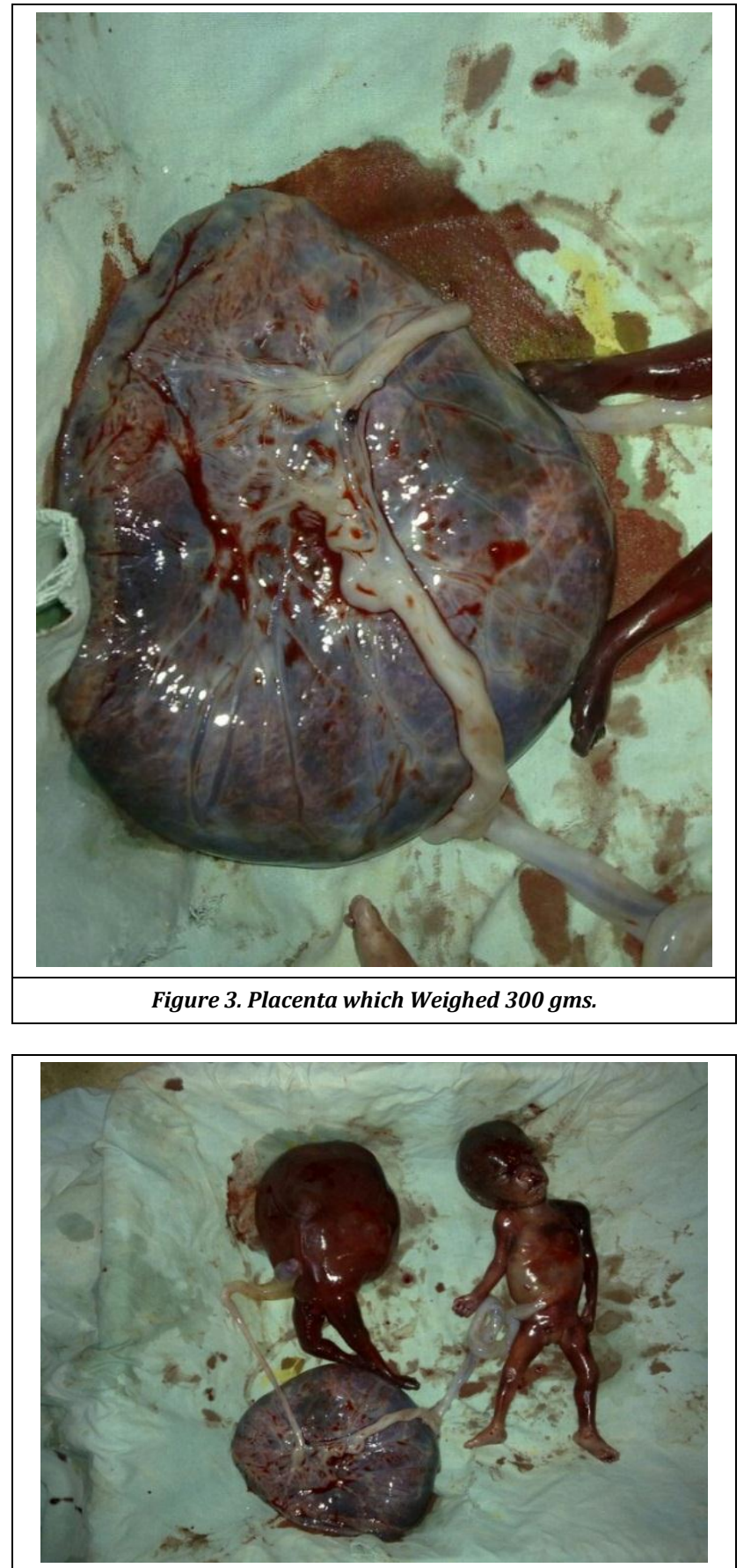

Figure 4. Monozygotic Twin with Acardius Acephalus Foetus

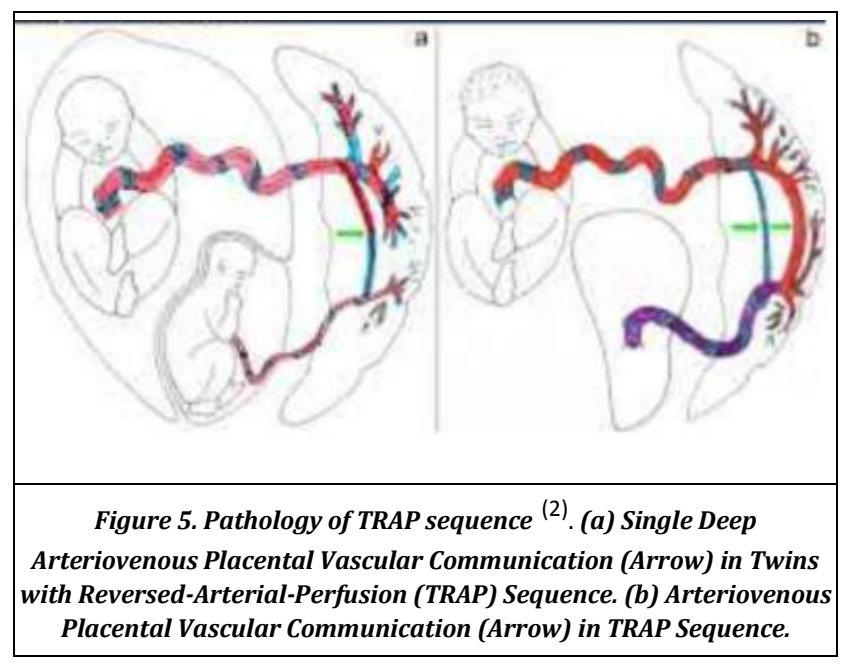

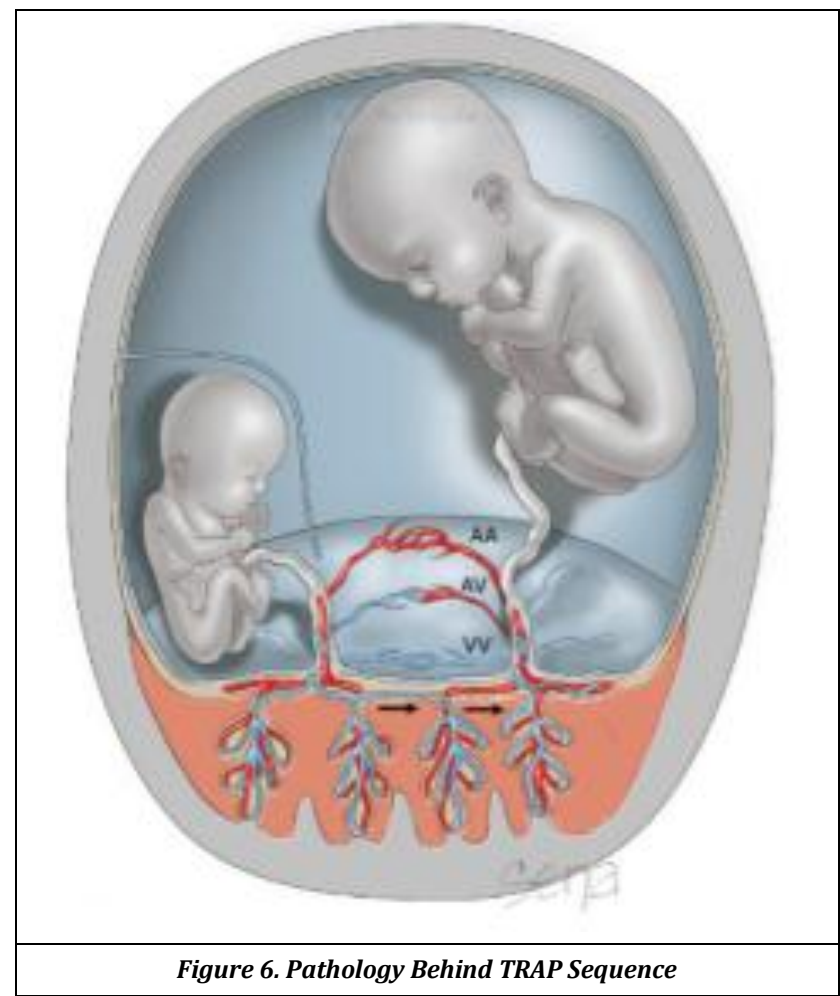

\section{PATHOLOGICAL DISCUSSION}

There are vascular connections in monozygotic twins. TTS is one of the manifestations affecting up to fifteen percent of these twins. TRAP sequence is one of the rare occurrence. (3)

DAS (1902) established 4 categories of acardiac twins based on their physical appearance(4)-

1. Acardius Acormus accounts for five percent and is rarest form which has cephalic structures with limited or no truncal development, umbilical cord is attached to the head $^{(5)}$.

2. Acardius Anceps or Myelacephalus accounts for eight percent, which is the most developed form and it has partially developed head with brain tissues and facial structures and identifiable limbs. This type is associated with a high risk for complications in the normal twin. ${ }^{(6)}$

3. Acardius Amorphous accounts for twenty five percent in which the foetus has no recognizable human form except for a uniform, skin covered mass containing the rudiments of cartilage, muscle, fat, bone, blood vessels and other tissues. ${ }^{(7)}$

4. Acardius Acephalus accounts for sixty two percent in which the foetus is characterised by lack of upper limbs, head and thoracic organs but the lower limbs are well developed. They may have an underdeveloped skull base.

In the TRAP sequence ${ }^{(8),}$ the acardiac twin acts as a recipient and depends on the normal donor (pump) twin for obtaining its blood supply via transplacental anastomoses and retrograde perfusion of the acardiac umbilical cord. Perfusion of the malformed foetus occurs via artery to artery and vein to vein anastomoses between the foetuses. The perfusion pressure of the donor twin overpowers that in the recipient twin, who thus receives reverse blood flow from its twin sibling. Deoxygenated umbilical arterial blood from the donor, thus, flows into the umbilical artery of the recipient, with its direction reversed. In these pregnancies, the umbilical cord 
from the acardiac twin branches directly from the umbilical cord of the normal twin. This blood flow is reversed from the normal direction (Figure1) leading to the name for this condition TRAP. As a result, there is better perfusion of the lower part of the deformed body. On the other hand, the upper part of the body, showing lack of head, heart and upper extremities remains poorly perfused. ${ }^{(9)}$

Normal twin (Donor) eventually develops high output failure because it is responsible for maintaining the circulation load of the donor twin may become extremely large resulting in heart failure. Doppler verification of reversed flow in the umbilical cord of the acardiac foetus helps in confirming the diagnosis.

\section{DISCUSSION OF MANAGEMENT}

Management of patients with pregnancies complicated by TRAP is still a controversial. Expectant management with serial ultrasound surveillance including foetal echocardiography is reasonable in the absence of poor prognostic features. If delivery is anticipated between 24 and 34 weeks' gestation, antenatal corticosteroid administration should be considered. Delivery may be indicated if signs of cardiac decompensation are noted. Maternal administration of digoxin and indomethacin ${ }^{(10)}$ have been reported as medical management of acardia, however, no series data are available. The treatment modalities include observation, $\mathrm{MgSO}_{4}$, beta mimetics administration to avoid pre-term labour and as described corticosteroid administration for foetal lung maturity.

Various Techniques have been used to interrupt the vascular communication between the twins in an effort to improve outcome of the normal pump twin.

\section{Amniodrainage}

involves removal of the excess amount of amniotic fluid (Polyhydramnios) through the process of amniocentesis. The procedure may only temporarily restore the balance in the amniotic fluid as the fluid may return back within few days. Thus, the procedure might require to be repeated after few days, but may result in numerous complications like PROM, preterm labour, rarely infections and abruption. The procedure is done to avoid uterine contractions due to over distended abdomen. Other procedures include-

- Invasive procedures like hysterotomy for the selective delivery of the acardiac twin.

- Intrafoetal ablation of the acardiac twin by alcohol,

- Radiofrequency,

- Laser or thermocoagulation,

- Ultrasound guided funicular occlusion by ligation, cord compression, thermocoagulation or

- Intrafunicular embolisation with foreign bodies and foetoscope guided funicular occlusion by ligation, laser or thermocoagulation.

- Blocking the vessels by coagulation using Nd: Yag laser and radiofrequency ablation under ultrasound guidance are now the first line of treatment.

\section{Intrafoetal Alcohol Ablation}

Some studies showed that absolute alcohol was being used to interrupt the blood supply to lesions by the process of chemosclerosis. This procedure was done under colour Doppler USG guidance.

\section{Intrafoetal Radiofrequency Ablation}

With this procedure, high-frequency alternating current is used to coagulate and desiccate tissue. Radiofrequency ablation (RFA) has become a favoured modality for treatment of twin-reversed arterial perfusion (TRAP) sequence. Without treatment, the mortality rate for the normal or pump twin in severe TRAP sequence exceeds 50 percent.

The procedure is also used for selective termination with other monochorionic twin complications (Bebbington, 2012). Under sonographic guidance, a 17- to 19-gauge RFA needle is directed into the base of the umbilical cord of the acardiac twin and inserted into its abdomen. After a 2-cm area of coagulation is achieved, colour Doppler sonography is applied to verify absent flow into the acardius. In several centers, survival rates for the normal twin following RFA have significantly improved (Lee, 2007; Livingston, 2007).

RFA was performed at approximately 20 weeks' gestation in 98 pregnancies with TRAP sequence reported by the North American Foetal Therapy Network (NAFTNet). The median gestational age at delivery was 37 weeks, and the neonatal survival rate was 80 percent. The major complication was prematurely ruptured membranes and preterm birth. Twelve percent were delivered at approximately 26 weeks (Lee, 2013).

RFA has generally been offered for TRAP sequence when the volume of the acardiac twin is large. In the NAFTNet series cited above, the median size of the acardius relative to the pump twin was 90 percent (Lee, 2013). Considering procedure-related risks, expectant management with close foetal surveillance is instead considered if the estimated weight of the acardius is below 50 percent of the pump twin (Jelin, 2010). Finally, acardiac twins are more likely to complicate monoamnionic gestations. In one recent series, pump twin survival following RFA was 88 percent in monochorionic diamnionic pregnancies but only 67 percent in monoamnionic pregnancies (Sugibayashi, 2016)

\section{Intrafoetal Laser Ablation}

It is a technique USG guided laser coagulation by using intraabdominal vessels like single umbilical artery, abdominal aorta, intra pelvic vessels to ablate acardiac twin.

A Neodymium Yttrium-Aluminum-Garnet (Nd:YAG) laser were used. ${ }^{(11)}$ YAG-laser occlusion of intraabdominal vessels of the acardiac twin and obliteration of the blood flow were used.

\section{Intrafoetal Monopolar Thermocoagulation}

These techniques include USG guided funicular occlusion by ligation with Foley cordostat, thermocoagulation, cord compression, intrafunicular embolization with foreign bodies like alcohol-soaked suture materials, fibrin clots, metallic coil.

\section{Conservative Management versus Invasive Treatment}

Perinatal mortality ranging from thirty five percent to fifty five percent has been associated due to the TRAP sequence.\{11,12\} Ultrasound-guided intrafoetal laser ablation or RFA is believed 
to be the current scenario choice for the treatment based on currently available data.

\section{CONCLUSIONS}

Acardiac twin can be diagnosed as early as possible by USG and Doppler in the first trimester itself. Diagnosing as early as possible helps in decreasing the perinatal mortality of the pump twin which also helps in diagnosing the heart failure of the normal twin and also preventing the preterm labour. First line of treatment is by blocking the vessel of acardiac twin by radio frequency ablation by USG guidance. Treating these pregnancies with TRAP sequence at suitable time period increases the survival of the normal twin by ninety five percent at approximate delivery between thirty six and thirty seven weeks.

\section{REFERENCES}

[1] D'Alton ME, Simpson LL. Syndromes in twins. Semin Perinatol 1995;19(5):375-86.

[2] Figueras MTF, Vaz Romero V, Poch FJS, et al. Teratoma of the placenta, a case report. Eur J Obstet Gynecol Reprod Biol 1989;32(2):169-72.

[3] Fisk NM, Ware M, Stanier P, et al. Molecular genetic etiology of twin reversed arterial perfusion sequence. Am J Obstet Gynecol 1996;174(3):891-4.

[4] Das L. Acardiacusanceps. J Obstet Gynaecol Br Emp 1902;2:341-55.
[5] Schinzel AAGL, Smith DW, Miller JR. Monozygotic twinning and structural defects. J Pediatr 1979;95(6):921-30.

[6] James WH. A note on the epidemiology of acardiac monsters. Teratology 1977;16(2):211-6.

[7] Napolitani FD, Schreiber I. The acardiac monster: a review of the world literature and presentation of 2 cases. Am J Obstet Gynecol 1960;80(3):582-9.

[8] Van Allen MI, Smith DW, Shepard TH. Twin reversed arterial perfusion (TRAP) sequence: a study of 14 twin pregnancies with acardius. Semin Perinatol 1983;7(4):285-93.

[9] Sogaard K, Skibsted L, Brocks V. Acardiac twins: pathophysiology, diagnosis, outcome and treatment. Six cases and review of the literature. Foetal Diagn Ther 1999;14(1):53-9.

[10] Ash K, Harman CR, Gritter H. TRAP sequence successful outcome with indomethacin treatment. Obstet Gynecol 1990;76(5 Pt 2):960-2.

[11] Moore TR, Gale S, Benirschke K. Perinatal outcome of forty-nine pregnancies complicated by acardiac twinning. Am J Obstet Gynecol 1990;163(3):907-12.

[12] Buntinx IM, Bourgeois N, Buytaert PM, et al. Acardiac amorphous twin with prune belly sequence in the cotwin. Am J Med Genet 1991;39(4):453-7. 